\title{
Ilha dos Búzios, Litoral Norte do Estado de São Paulo: Aspectos G eológicos e Petrográficos
}

\author{
Francisco R. Alves \& Celso B. Gomes \\ Departamento de Mineralogia e G eotectônica - Instituto de Geociências - USP \\ Rua do Lago 562, CEP 05508-900, São Paulo, SP
}

Palavras-chave: Magmatismo alcalino, Ilha dos Búzios.

\section{RESUMO}

Rochas sieníticas cretácicas introduzidas em charnoquitos precambrianos constituem a geologia da Ilha dos Búzios $\left(7,5 \mathrm{~km}^{2}\right)$, situada no litoral norte do Estado de São Paulo, região sudeste do Brasil. Ambas unidades litológicas estão cortadas por grande número de diques, orientados preferencialmente para NE e variáveis em composição. Os sienitos podem incluir xenólitos de charnoquitos e de rochas máficas, além de também conter cavidades miarolíticas, de forma irregular e preenchidas ou não com quartzo.

As rochas alcalinas, cobrindo aproximadamente $90 \%$ da ilha, são dominantemente de granulação grossa e variam em composição de álcali feldspato sienitos a quartzo-álcali feldspato sienitos. Localmente, podem ser também encontradas variedades sieníticas de granulação fina.

Os diques, de ocorrência generalizada por toda a ilha, são enquadrados no grupo félsico, que reúne litologias variando de fonólitos a traquitos e riólitos (microgranitos), ou no máfico-ultramáfico, este consistindo principalmente em diabásios, microdioritos e lamprófiros.

Feldspato alcalino (micromesopertita com pequeno predomínio das fases albíticas) é o mineral mais abundante das rochas sieníticas. Outros constituintes incluem clinopiroxênio (diopsídio-augita variando até egirina-augita), que se mostra comumente substituído por anfibólio/biotita, além de opacos (magnetita, ilmenita), apatita, titanita e zircão como principais acessórios. Os diques félsicos podem conter outros feldspatos, como sanidina e albita, quer na condição de micro a fenocristais, quer como membros da massa fundamental; feldspatóides (nefelina, sodalita) estão também presentes em alguns microssienitos. Os diques máfico-ultramáficos, em particular os de lamprófiros, são caracterizados por uma associação mineralógica primária consistindo em olivina, clinopiroxênio (augita titanífera) e anfibólio (kaersutita), além de massa fundamental contendo material vítreo e analcita. Digna também de registro nos lamprófiros é a presença de pequenos grãos ou agregados de ocelos carbonáticos de formação primária. Diques de natureza mais basáltica possuem plagioclásio (andesina-labradorita) zonado, feldspato alcalino intersticial e clinopiroxênio (diopsídio-augita), anfibólio, biotita e opacos como principais minerais ferromagnesianos.

Não obstante as diferenças petrográficas e químicas, os corpos alcalinos formando as ilhas de Vitória, Búzios, São Sebastião e Monte de Trigo, todas elas situadas na costa oriental do Estado de São Paulo, parecem corresponder a eventos magmáticos apresentando o mesmo condicionamento geológico. Eles muito provavelmente representam intrusões contemporâneas associadas a anomalias térmicas no manto e estão intimamente ligados à evolução tectônica Mesozóica da porção sudeste do Brasil. 
Keywords: Alkaline magmatism, Búzios Island.

\section{ABSTRACT}

Cretaceous syenitic rock-types intruded into Precambrian charnockites characterize the geology of Búzios island $\left(7.5 \mathrm{~km}^{2}\right)$ in area off the northern coast of the State of São Paulo, SE Brazil. Both lithologic units are cut by a large number of dykes, mostly NE-trending and quite variable in composition. The syenites may include charnockitic and mafic rock xenoliths and also contain quartz-filled, irregular miarolitic cavities.

The alkaline rocks, corresponding to approximately $90 \%$ of the whole island, are dominantly coarse-grained and range in composition from alkali feldspar syenites to quartz-alkali feldspar syenites. Locally, fine-grained syenitic types are also found. Dykes are widespread over the island and can be placed into the felsic group, which includes lithologies varying from phonolites to trachytes to rhyolites (microgranites), or into the mafic-ultramafic group, the latter mainly consisting of diabases, microdiorites and lamprophyres.

Alkali feldspar (micromesoperthite with slight dominance of albititic phases) is the most abundant mineral in syenitic rocks. Additional components are clinopyroxene (diopside-augite ranging to aegirine-augite), commonly replaced by amphibole/biotite, and opaques (magnetite, ilmenite), with apatite, sphene and zircon as accessories. The felsic dykes may contain other feldspars (sanidine and albite) either as micro- to phenocrysts or as groundmass phases; feldspathoids (nepheline, sodalite) are also found in some microsyenites. The mafic-ultramafic dykes, in particular the lamprophyres, are mainly characterized by a primary mineral assemblage consisting of olivine, clinopyroxene (titanian augite) and amphibole (kaersutite), besides a groundmass bearing glassy material and analcite. Also to be noted in the lamprophyres is the presence of small grains or aggregates of carbonate ocelli as primary phases. Dykes showing a more basaltic composition have zoned plagioclase (andesine-labradorite), interstitial alkali feldspar and, as main ferromagnesian minerals, clinopyroxene (diopside-augite), amphibole, biotite and opaques.

In spite of the petrographic and chemical differences, the alkaline bodies forming the islands of Vitória, Búzios, São Sebastião and Monte de Trigo, all found off the northern coast of the State of São Paulo, seem to be part of magmatic events related to the same geologic setting. They probably represent contemporaneous intrusions derived from an anomalously hot mantle and are closely associated with the Mesozoic tectonic evolution of Southern Brazil.

\section{INTRODUÇÃO}

A Província da Serra do Mar, proposta por Almeida (1983) para o conjunto de rochas alcalinas que se dispõem paralelamente à faixa litorânea São Paulo - Rio de Janeiro, muito tem a ser estudada, uma vez que apenas algumas dessas ocorrências são razoavelmente conhecidas, bem como contam com informações geológicas, mineralógicas, petrológicas, geoquímicas e geocronológicas. Aqui estão incluídas as ocorrências das ilhas de Búzios, Monte de Trigo, São Sebastião e Vitória (Figura 1), além das continentais da Serra Mantiqueira, como Itatiaia, Morro Redondo e Passa Quatro.

Pela sua grande extensão e importância socioeconômica, a Ilha de São Sebastião foi a primeira ocorrência não-continental a ser pesquisada geologicamente (Freitas, 1947), com os trabalhos tendo continuidade nas décadas posteriores (Hennies, 1964; Hennies \& Hasui, 1968, 1977; Bellieni et al., 1990; Garda, 1995). A Ilha do
Monte de Trigo recebeu alguma atenção por parte de Coutinho \& Melcher (1973) e, mais recentemente, começou a ser trabalhada do ponto de vista geoquímico (Enrich \& Ruberti, 1999); já a de Vitória foi investigada mais detidamente por Motoki \& Gomes (1984), Motoki (1986) e Motoki et al. (1987). Por sua vez, a Ilha dos Búzios, após reconhecimento geológico preliminar feito por Björnberg \& Ellert (1955), apenas voltaria a ser objeto de pesquisa no final da década passada por Alves (1997), em sua tese de doutoramento.

Este texto se constitui na mais recente e abrangente fonte de informações e dados sobre ela, já divulgados preliminarmente em eventos científicos (Alves \& Gomes, 1999, 2000; Alves et al., 1999, 2000). Objetiva-se aqui primordialmente oferecer novas informações sobre a geologia da Ilha, descrever os principais tipos litológicos ali encontrados e, ainda, discutir a colocação e evolução do magmatismo alcalino que a atingiu. 


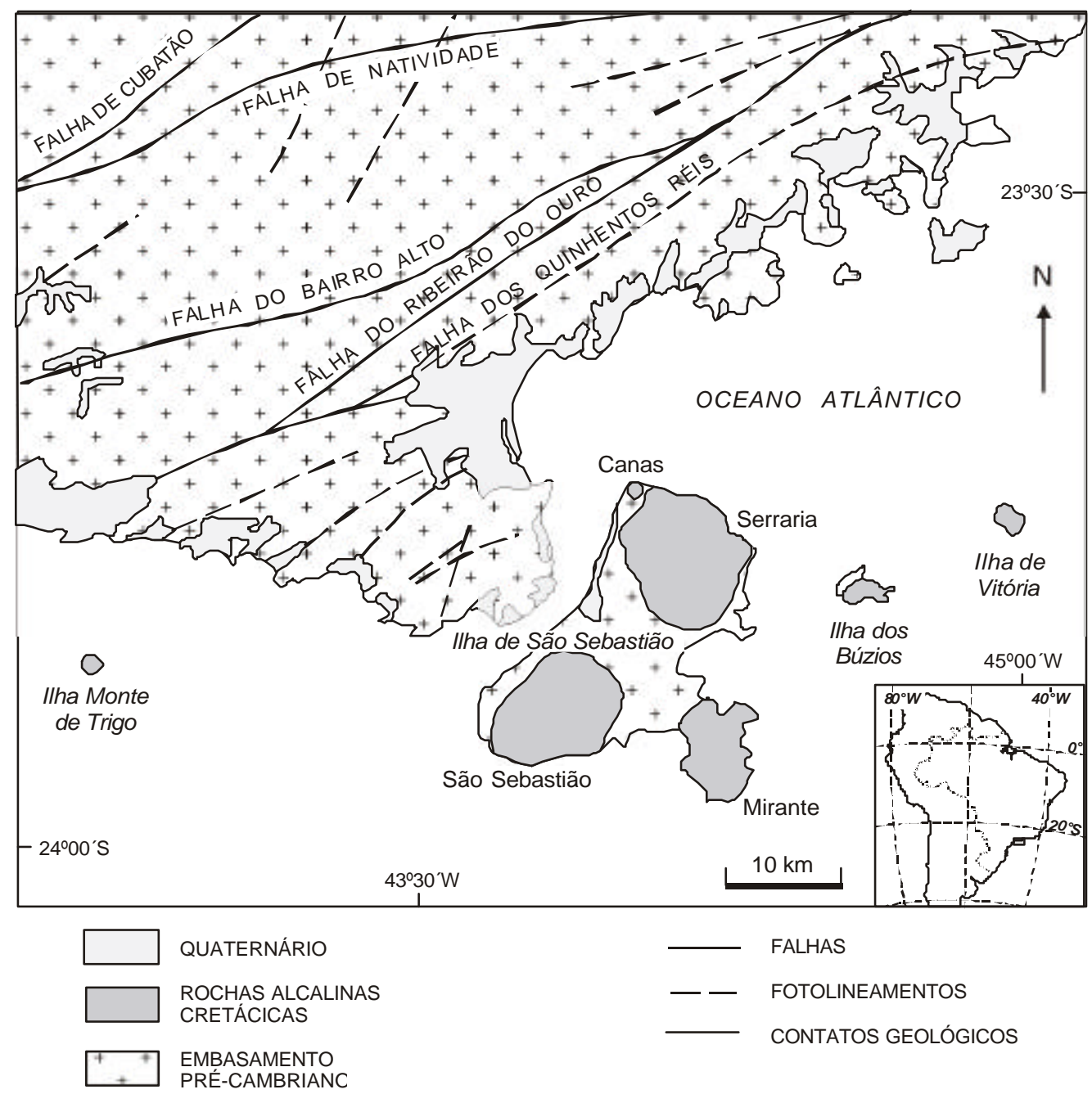

Figura 1: Mapa de localização da llha dos Búzios.

\section{GEOLOGIA DA ILHA}

A Ilha dos Búzios, que inclui a ilhota chamada Somítica, pertence ao município de Ilha Bela, no litoral norte do Estado de São Paulo, e situa-se a leste da conhecida Ilha de São Sebastião. Do continente dista pouco mais de $30 \mathrm{~km}$. Nas suas vizinhanças, existem outras seis ocorrências de rochas alcalinas plutônicas: a Ilha do Monte de Trigo, a Ilha de Vitória e os "stocks" de São Sebastião, da Serraria e do Mirante, na Ilha de São Sebastião, mais o suposto corpo "das Canas". Nas mesmas ilhas e no litoral próximo, entre as cidades de São Sebastião e Ubatuba, ocorre ainda grande quantidade de diques alcalinos de litologia e idade variadas. Os corpos plutônicos, incluindo o de Búzios, distribuem-se por faixa NE de $20 \mathrm{~km}$ de largura e $80 \mathrm{~km}$ de extensão.
Dados geocronológicos constantes do trabalho de Alves (1997), incluindo determinações por $\mathrm{K} / \mathrm{Ar}$ e $\mathrm{Rb} / \mathrm{Sr}$ de concentrados minerais (biotita e anfibólio) e rocha total, permitem sugerir como idade média preferencial para

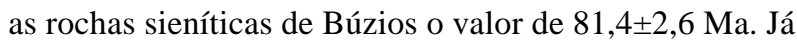
para os diques, não obstante a limitação das informações considerando o erro analítico das análises, a idade média é de 79,0 $02,4 \mathrm{Ma}$. Ainda que os dados disponíveis para as ocorrências das ilhas vizinhas (Vitória, São Sebastião e Monte de Trigo) mereçam também alguns reparos, notase no geral convergência dos valores em torno de $80 \mathrm{Ma}$, que poderia, assim, representar a idade do magmatismo alcalino na área.

A Ilha ocupa área aproximada de $7,5 \mathrm{~km}^{2}$ e apresenta forma irregular, estendendo-se por mais de $3 \mathrm{~km}$ e cerca 
de $5 \mathrm{~km}$, respectivamente, nas direções NS (Ponta SulPonta do Arpoador) e EW (Ponta das Pitangueiras-Ponta Leste) (Figura 2). Sua parte oeste é mais ampla, sustentada por espigão NE com até $400 \mathrm{~m}$ de altura, e se prolonga em faixa mais estreita, como espigão e morros mais baixos (até $250 \mathrm{~m}$ ), para leste. As encostas terminam em costões rochosos, que descem diretamente para o mar, com gradientes de $30^{\circ}$ até verticais. O solo é comumente raso, seco e pedregoso, contendo por vezes concreções e restos de minerais e rochas. Os processos erosivos, incluindo o escorregamento de blocos, foram mais eficientes que os intempéricos, levando, dessa forma, à formação de grande quantidade de blocos, de lages freqüentes e de solos rasos.

As estruturas têm direção predominante N50-70E e de forma subordinada N40W, com caimento vertical na maioria das vezes. As fraturas se constituem na feição mais visível nas rochas, apresentando-se homogeneamente distribuídas e com o mesmo padrão direcional. Bandamentos e foliação acham-se restritos às encaixantes charnoquíticas. Os falhamentos observáveis nos afloramentos são raros.
Diques estão presentes por toda a Ilha, mostrando-se intrusivos tanto nas encaixantes quanto nas rochas alcalinas, e formando dois agrupamentos distintos: félsicos e máficos/ultramáficos. Os primeiros são de coloração clara a verde escuro, enquanto que os segundos exibem tonalidade cinzenta escuro a preta. Em geral, apresentam traçado retilíneo e espessura decimétrica a métrica. Representam diversas gerações, embora as relações cronológicas entre eles e com as rochas alcalinas associadas não sejam muito claras.

As encaixantes consistem basicamente em charnoquitos, rochas em geral de coloração verde escuro, granulação grossa a muito grossa e com orientação dos feldspatos. Na forma de intercalações, formando leitos contínuos ou não, ocorrem gnaisses mais claros, gnaisses alasquíticos finos e cisalhados, além de rochas blastomiloníticas. São também comuns as associações com camadas concordantes anfibolíticas ou metabásicas (variedades dioríticas a plagioclasíticas com ortopiroxênio). Não foram observados contatos bruscos entre as encaixantes e as ro-

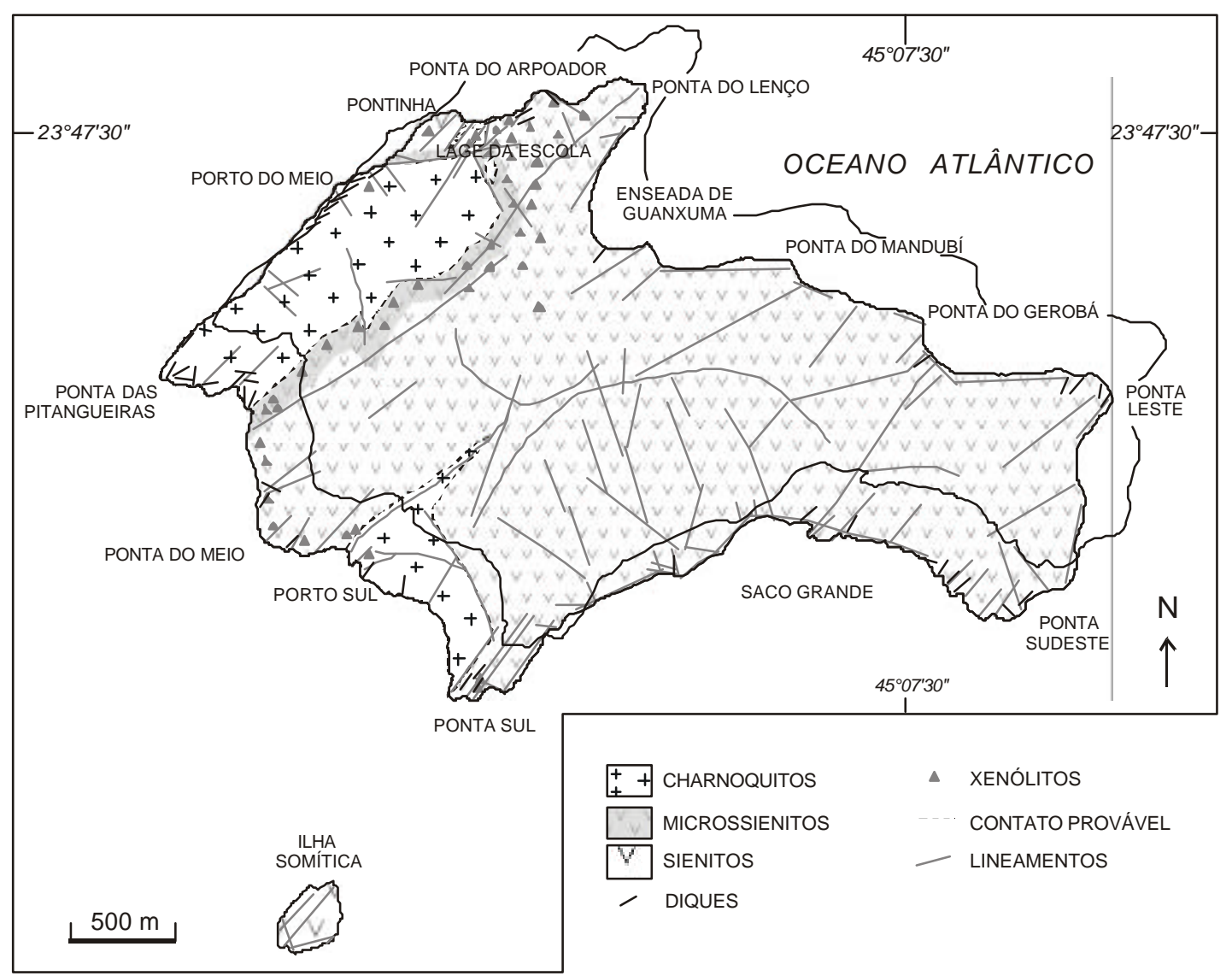

Figura 2: Mapa geológico da llha dos Búzios (simplificado de Alves, 1997). 
chas alcalinas; mais raramente esses contatos se dão através de falhas.

As rochas alcalinas, constituindo aproximadamente 90\% da Ilha, são dominantemente de natureza sienítica, com tipos os mais variados, além de portadoras de xenólitos e de cavidades miarolíticas de dimensões decimétricas e formas irregulares, e contendo ou não preenchimento de quartzo. Os xenólitos são comuns por toda a região próxima dos contatos, sendo o tipo principal (I) constituído de rochas charnoquíticas e de máficas. Podem aparecer concentrados, 20 a 30\% da área exposta, ou ainda dispersos, cobrindo então não mais de $5 \%$ da superfície. Os charnoquíticos podem ocorrer na forma de cristal único de feldspato ou como agregados de dimensões métricas. Os máficos são muito freqüentes, aparecendo isoladamente ou associados aos primeiros. Apresentam dimensões inferiores e se mostram em geral mais angulosos. Um segundo tipo de xenólitos (II) é representado pelos enclaves centimétricos arredondados.

\section{PETROGRAFIA}

As rochas sieníticas e microssienitícas associadas podem ser reunidas em dois grandes grupos: as sem ou com apenas traços $(<1 \%)$ de quartzo e aquelas portadoras de $1 \%$ até $5 \%$ do mineral. Não obstante menos comuns, tipos contendo teores acima desse limite estão também presentes, correspondendo principalmente às variedades granofíricas. No diagrama classificatório QAPF (Le Maitre, 1989), as rochas sieníticas tendem a se concentrar nos campos dos álcali feldspato sienitos e quartzo-álcali feldspato sienitos. Já as rochas de granulação média a fina são, adicionalmente, encontradas no campo dos álcali feldspato (micro) granitos.

\section{Rochas sieníticas}

\section{Álcali feldspato sienitos}

Esta é a litologia mais comum da Ilha, aparecendo indistintamente em todos os seus cantos. São rochas claras e de aspecto maciço, de granulação em geral grossa e variando quanto ao arranjo dos grãos de equigranulares, de ocorrência mais comum, a inequigranulares. A textura mais típica é a foiaítica, que passa a hipidimórfica e alotriomórfica nas variedades mais inequigranulares e mais ricas em quartzo; mais raramente reconhece-se também a textura traquitóide.

O feldspato, o seu principal constituinte, acha-se re- presentado por uma micromesopertita de contorno subretangular, com predomínio da fase sódica, e caracterizada pela presença de indivíduos com dimensões centimétricas e geminação simples, do tipo Carlsbad. Ao contrário das fases sódicas, em geral mais limpas, as potássicas não são geminadas possuem aspecto sujo e se mostram crivadas de inclusões. São dominantemente do tipo "string" (tigrada), com as lamelas sódicas mais homogêneas e as potássicas formando duas gerações variáveis em tamanho. É comum a presença de fases albíticas dispostas nas bordas dos indivíduos ou como agregado intersticial. O quartzo tem concentração muito variável e pode ocorrer como grãos isolados ou formando áreas maiores, em geral interstiticiais. Plagioclásio, na forma de cristais individualizados, não foi identificado.

Os minerais fêmicos representam não mais de $10 \%$ dessas rochas, reconhecendo-se, em ordem de frequiência, biotita, clinopiroxênio e anfibólio. Na condição de acessórios, opacos e apatita são as fases mais presentes, ocorrendo ainda titanita, zircão e allanita. Biotita, com pleocroísmo marrom a marrom-esverdeado em Y-Z, apresenta-se inalterada, formando placas submilimétricas a milimétricas e, comumente, contendo inclusões de acessórios. O clinopiroxênio assume formas e posturas diversas, desde grãos isolados até agregados, ou ainda como inclusões na biotita. As características ópticas indicam que a sua composição é variável, ajustando-se à seqüência diopsídio-augita-hedenbergita até egirina-augita. Exibem coloração pardacenta e ausência de zoneamento ou são zonados, com as bordas dos grãos apresentando cor esverdeada e baixo ângulo de extinção (XÙc). O anfibólio é freqüentemente manchado ou zonado. Ocorre envolvendo o clinopiroxênio, ou mesmo incluindo-o, ou ainda associado à biotita em relação variada. A coloração em Y-Z é esverdeada a amarelada, em tonalidades diversas, e mais raramente azulada ou acinzentada. As feições ópticas indicam variações composicionais dentro dos anfibólios cálcicos a cálcio-sódicos. Os opacos reúnem magnetita e ilmenita, com nítida dominância da primeira fase. São onipresentes, com teores constantes em torno de 1 a $2 \%$, chegando por vezes a alcançar até $5 \%$. Formam grãos isolados ou intercrescidos, sendo comum a presença de bordas de titanita.

\section{Q uartzo-álcali feldspato sienitos}

Das rochas sieníticas, cerca de $20 \%$ caem nessa classificação. Esses sienitos têm distribuição geográfica regular, inexistindo, porém, nas porções internas do maciço. São rochas de granulação grossa, equi a inequigranulares, com variações texturais de hipidiomórfica a alotriomórfica, e exibindo cores escuras esverdeadas a cinzentas. Inclu- 
em os chamados tipos híbridos, semelhantes aos charnoquitos afins, que contêm restos de charnoquito e outras heterogeneidades, com rápidas alternâncias de granulação e finos bandeamentos descontínuos. Nessas rochas estão presentes as cavidades miarolíticas típicas.

A exemplo dos sienitos anteriores, são rochas possuindo baixo teor de minerais ferromagnesianos, que tendem a ocorrer espalhados ou concentrados nas faixas de granulação mais fina. Apesar da proporção mesopertitasfêmicos ser mantida, elas se distinguem, no entanto, pela maior concentração em anfibólio e, obviamente, pela maior riqueza em quartzo. Outras diferenças detectadas incluem a maior presença de produtos de alteração, sobretudo carbonatos.

A participação da mesopertita é a mesma, havendo, porém, mudança no seu padrão, que se torna mais irregular. O quartzo forma grãos isolados, xenomórficos, ou se dispõe entre os cristais de feldspato. Nessas rochas aparecem os intercrescimentos granofíricos, micrográficos e os "finger print" de Smith \& Brown (1988). Conservadas outras características, o anfibólio é semelhante ao dos sienitos anteriores, mostrando-se, contudo, melhor desenvolvido, na forma de grãos alongados. Apresenta alteração para carbonatos e se faz acompanhar de quartzo, notando-se ainda aumento de sua quantidade e concomitante diminuição dos teores de clinopiroxênio e biotita. Além disso, os agrupamentos registram mais a associação anfibólio-opacos-apatita.

O clinopiroxênio é do tipo diopsídico-augítico e aparece mais como restos no interior dos filossilicatos coloridos. Algumas amostras contêm também restos reconhecíveis de ortopiroxênio alterado. A biotita forma palhetas isoladas, de menor tamanho, ou concentra-se na periferia de outros minerais.

\section{Rochas microssieníticas}

Estas rochas, mostrando variação para traquitos, estão presentes na Ilha quer como fácies plutônica, quer na forma de diques. São rochas equigranulares até seriadas, poucas vezes porfiríticas, e de granulação média. A sua coloração é igualmente variável, com as rochas de diques apresentando em geral cores claras, enquanto as plutônicas das zonas de contato tendem a exibir tonalidades escuras a esverdeadas. A despeito da coloração, são todas rochas leuco a hololeucocráticas, com o teor de máficos dificilmente ultrapassando os 10\%. Além das variações texturais, a modificação mais notável observada é no teor de quartzo, com alguns tipos chegando até $20 \%$ ou mais. Nas variedades traquíticas, contudo, ele não atinge os 10\%. Essas variações mineralógicas e texturais acham-se ligadas à forma de ocorrência e ao posicionamento geográfico das amostras. Assim, os microssienitos das zonas de contato quase sempre possuem quartzo, e acima dos $5 \%$. Por outro lado, os tipos que ocorrem na forma de bolsões, ou como tratos de limites indefinidos nos sienitos, tanto podem conter ou não o mineral. Já os diques intrusivos nos charnoquitos são sempre portadores de quartzo.

\section{Álcali feldspato microssienitos}

Texturalmente são rochas holocristalinas, variando de panidiomórficas a hipidiomórficas granulares, com a mesopertita (constituindo invariavelmente 90 a $95 \%$ da amostra) em arranjo aleatório ou com leve tendência ao subparalelismo. Com o aparecimento do quartzo, observam-se modificações não só mineralógicas como texturais, com o caráter panidiomórfico e a forma geométrica dos cristais de feldspato cedendo lugar a um arranjo mais hipidiomórfico a alotriomórfico.

Mineralogicamente, quando comparadas aos álcali feldspato sienitos, essas rochas diferem pela maior abundância de anfibólio entre os fêmicos, seguido de clinopiroxênio e opacos. Aparentemente, a quantidade de anfibólio aumenta na medida em que cresce a do quartzo. A biotita inexiste ou pouco representa. Já o principal acessório é o zircão, estando ausentes, ou pouco presentes, a apatita e a titanita. Ocasionalmente, aparece allanita. Plagioclásio também não foi reconhecido. Carbonatos constituem o principal produto de alteração dessas rochas, ocorrendo intersticialmente ou na forma granular em associação com os demais minerais.

A mesopertita, do tipo lamelado (tigrado), é a mais típica das rochas da Ilha, com um padrão bastante regular e invariavelmente presente em todas as amostras. Quanto aos minerais fêmicos, raramente bem formados, o anfibólio é o que apresenta contornos mais regulares, além de pleocroísmo constante em $\mathrm{Z}$ em tonalidades variáveis de verde, que passa, no entanto, para azul intenso nas bordas dos grãos. Por sua vez, o clinopiroxênio tende a mostrar pleocroísmo verde forte, comum aos tipos egirínicos, junto às margens dos cristais.

\section{Q uartzo-álcali feldspato microssienitos}

Quando confrontadas com os quartzo-álcali feldspato sienitos, essas rochas não exibem grandes diferenças quanto à mineralogia, a mais importante delas residindo no aumento da concentração de quartzo, que leva até à formação de variedades do tipo granítico e granofírico. Os produtos tardios de alteração são agora mais abundantes, afetando principalmente os minerais fêmicos, que, à exceção dos opacos, chegam mesmo a inexistir em certas amostras. Ao contrário dos tipos microssieníticos descritos previamente, a mesopertita passa aqui a apresentar padrão mais variado. 
As mudanças mais significativas encontradas dizem respeito, no entanto, a aspectos texturais, como granularidade e forma dos grãos. O caráter inequigranular está quase sempre presente e a forma e o arranjo dos grãos aponta para texturas alotriomórficas granulares. Igualmente característico desse conjunto litológico é a presença de zonas xenolíticas coalescidas ao restante da rocha ou de xenocristais. Aqui estão incluídos sejam minerais isolados, com dimensões superiores e distintos dos existentes no resto da rocha (por exemplo, plagioclásio, feldspato alcalino), sejam fragmentos das encaixantes charnoquíticas. Da mesma forma, a presença de tipos de granulação média, com intercrescimentos granofíricos e micrográficos, em que o quartzo assume hábito cuneiforme e distribuição regular, ao lado de se associar ao quartzo do tipo moldura, que pode envolver porção da rocha. Podese dizer que esse quartzo é mais típico nas rochas de diques, enquanto que o granular e o granofírico mais comum às rochas das zonas de contato.

\section{Diques félsicos}

Este grupo é, petrograficamente, muito diversificado, incluindo os microssienitos descritos no item anterior, além de tipos litológicos supersaturados (riólitos) a insaturados (fonólitos). Os primeiros são encontrados próximos aos charnoquitos e nas zonas de contato; já os segundos ocorrem comumente na extremidade leste da Ilha e no Saco Grande. Por sua vez, os tipos saturados, quer microssieníticos como traquíticos, estão presentes por toda a Ilha. Em geral, os tipos mais ricos em $\mathrm{SiO}_{2}$ mostram-se intrusivos em rochas charnoquíticas, enquanto os mais empobrecidos têm como encaixante as rochas sieníticas.

\section{Álcali feldspato ( \pm quartzo) microssienitos}

São rochas similares às descritas como fácies plutônica e ocorrem principalmente na forma de diques. A textura é panidiomórfica, a mesopertita lamelada (tigrada) e o quartzo, quando presente, é representado pelo tipo "moldura".

\section{Sodalita fonólitos e nefelina (sodalita) microssienitos}

São rochas de aspecto diversificado, raramente foliadas, com textura porfirítica e granulação média a muito fina (afanítica). A cor é também variável, indo de cinzento-esverdeada a preta ou ainda de cinzenta a rósea. $\mathrm{O}$ arranjo porfirítico mostra comumente um mosaico de nefelina idiomórfica sobre o qual se sobressaem fenocristais de feldspato micropertítico a micromesopertitítico, com dimensões de 1 a $10 \mathrm{~mm}$ e contornos retangulares, e que contém, ao lado de albita, como pequenas ripas dispostas ao acaso ou formando feixes, minerais fêmicos e acessórios dispersos. Em variedades de maior granulação, o arranjo é semelhante ao da textura intergranular ou intersertal. A sodalita aparece com a mesma disposição da nefelina.

Os fêmicos, que juntamente com os acessórios, constituem de 10 a $25 \%$, excepcionalmente até um pouco mais dessas rochas, estão representados por clinopiroxênio esverdeado, zonado e de natureza egirínica, além de biotita e anfibólio. O primeiro tem forma prismática e não raramente exibe núcleo de anfibólio ou cresce sobre ele. Também ocorre incluso nos feldspatóides ou ocupando os interstícios dos feldspatos. O anfibólio é do tipo sódico, com pleocroísmo de coloração esverdeada a azulada em $\mathrm{Z}$, e características semelhantes às do clinopiroxênio ou formando indivíduos maiores. Por vezes, estes últimos são poiquilíticos, com inclusões principalmente de feldspato e clinopiroxênio. A biotita forma pequenas placas, em geral idiomórficas, e apresenta pleocroísmo variando de marrom escuro a preto em $\mathrm{Z}$.

Os acessórios consistem em fases silicáticas de ocorrência mais rara, como enigmatita, lamprofilita, astrofilita e eudialita, além de eventual fluorita. Comumente, são idiomórficos e aparecem como grãos isolados ou em pequenos grupos, dispersos ou ocupando interstícios de outros minerais.

As variedades classificáveis como microssienitos possuem em geral mineralogia muito semelhante entre si, com as pequenas diferenças correndo por conta da ausência de silicatos raros, da presença de anfibólio como único fêmico e da maior riqueza em sodalita, suplantando a da nefelina.

\section{Traquitos}

Neste grupo estão inseridos apenas traquitos e quartzo-álcali feldspato traquitos, uma vez que não foram reconhecidas variedades portadoras de nefelina.

O traquito típico de Búzios é caracterizado pela presença de textura porfirítica, com fenocristais idiomórficos de feldspato alcalino, na forma de lamelas, imersos em matriz fina a muito fina consistindo em ripas alongadas do mesmo mineral. O feldspato é uma micropertita de padrão variado, com geminação do tipo Carlsbad, múltipla e complexa. Os fenocristais têm dimensões variáveis, de 0,5 a $10 \mathrm{~mm}$, e representam 5 a $10 \%$ da rocha. Albita ocorre intersticialmente entre as ripas dos indivíduos maiores de micropertita ou ocupando as periferias dos cristais.

Ainda quanto à mineralogia, essa rochas têm anfibólio, acompanhado ou não de biotita, opacos e clinopiroxênio, como o componente fêmico mais importante, e mesmo único em algumas amostras. Trata-se de variedade ocorrendo na forma de prismas alongados, em geral paralelos 
à orientação da textura da rocha, e exibindo pleocroísmo em verde escuro ou azulado na direção Z. Essas rochas podem ter quantidade variável de quartzo, até mais de $5 \%$.

Um outro tipo de rocha traquítica, também comum na Ilha, apresenta micropertita "tigrada" seja na forma matricial como de fenocristais. Aqui, a granulação da matriz é quase milimétrica e os fenocristais maiores possuem dimensões variando de 1 a mais de $10 \mathrm{~mm}$. Eles exibem padrão de geminação complexo e estão crivados por cristais de biotita, opacos e clinopiroxênio, delimitando formas sucessivas de crescimento com núcleos limpos, isentos de inclusões. A matriz é formada por ripas longas de feldspato, encostadas umas às outras, com predomínio de albita, além de traves sem a fase potássica.

Ao lado de anfibólio, principalmente nas variedades de granulação mais grossa, aparecem ainda biotitas, com pleocroísmo marrom em Y e Z, clinopiroxênio e opacos, estes últimos ausentes no primeiro tipo, e agora em grande abundância. Como acessórios, estão presentes apatita, titanita e zircão.

\section{Riólitos}

São rochas finas, de textura hipidiomórfica granular a inequigranular, e com pequeno número de ocorrências, todas elas na face oeste da Ilha. O feldspato consiste em uma mesopertita do tipo "tigrado", de aspecto pigmentado, contorno sub-retangular, e presente na forma de indivíduos isolados ou como agregados. Juntamente com o quartzo, responde por 90 a $95 \%$ da rocha, sendo o teor deste último variável de 20 a 30\%. Demais constituintes incluem biotita, opacos, fluorita, zircão e produtos de alteração (carbonatos).

Algumas amostras são portadoras de xenocristais de natureza quartzo-feldspática (micro a mesoperita), comumente aparecendo na forma de um mosaico xenomórfico de granulação fina, circundados por auréolas sucessivas reunindo diferentes minerais (feldspato microrradial, opacos, carbonatos etc.).

Nas regiões de contato, essas rochas apresentam visíveis evidências de microbrechação, como indicado pela matriz vítrea a criptocristalina e presença de clastos angulosos de minerais e de rochas, todos provenientes das encaixantes, ao lado da maior riqueza em fluorita.

\section{Aplitos}

Estas rochas são encontradas por toda a Ilha na forma de veios antes que diques. A composição mineralógica é muito variada e tem mesopertita "tigrada" como fase dominante, perfazendo, com ou sem quartzo, 90 a $95 \%$ da moda. A textura é tipicamente aplítica, por vezes inequigranular, com cristais maiores de feldspato; a granulação é fina, não ultrapassando a $0,5 \mathrm{~mm}$. Quartzo pode estar ausente ou chegar até $20 \%$, caracterizando, respectivamente, rochas sieníticas com feldspato alcalino e feldspato alcalino+quartzo. Como constituintes menores, são reconhecidos, principalmente, opacos, biotita, anfibólio e titanita.

\section{Diques máficos-ultramáficos}

Estas rochas, excluídas algumas variedades apresentando características muito particulares, podem ser enquadradas, do ponto de vista textural e mineralógico, em dois grandes grupos, diabásico e lamprofírico. Adicionalmente, reconhece-se também a presença de tipos microdioríticos (andesíticos).

\section{Diques diabásicos}

Em função principalmente de sua posição geográfica e/ou estratigráfica, esses diques são colocados em dois conjuntos distintos, os pós-sienitos e os pré- a sin-sienitos.

O primeiro distingue rochas maciças, de coloração cinzenta escuro a preta e granulação fina a afanítica. A textura é holocristalina e variável de subofítica a granular. Os minerais félsicos representam 50 a $60 \%$ da moda e têm plagioclásio $\left(\mathrm{An}_{35-60}\right)$, de hábito ripiforme, geminação polissintética e zoneamento normal como fase dominante; subordinadamente aparece feldspato alcalino na forma intersticial.

Os constituintes ferromagnesianos, formando grãos isolados ou agregados, ocupam os interstícios ou moldam as extremidades dos cristais de feldspato. Eles estão representados por anfibólio, de hábito prismático ou fibroso e coloração esverdeada em Z, biotita marrom e restos de clinopiroxênio, inclusos no anfibólio. Opacos estão invariavelmente presentes em formas as mais variadas, enquanto apatita e titanita são os acessórios mais freqüentes. Os produtos de alteração incluem carbonatos e clorita intersticial.

O segundo reúne rochas mostrando características próprias, com destaque para os seus aspectos texturais, onde se observam variações de blastossubofítica a granoblástica, hornfélsica, além da presença de minerais poiquiloblásticos. Possuem coloração cinzenta escura a preta e granulação média a fina, chegando por vezes a afaníticas. Em geral, são rochas maciças, que se apresentam intrusivas em sienitos ou associadas a charnoquitos; invariavelmente, estão ligadas a zonas xenolíticas. Do ponto de vista mineralógico, destacam-se por conter dois 
tipos de piroxênio, ao lado de plagioclásio $\left(\mathrm{An}_{35-50}\right)$, de contorno retangular e disposição subparalela, formando comumente cristais poiquiloblásticos com inclusões de ortopiroxênio. Em rochas de caráter mais diorítico ou mesmo monzodiorítico, o plagioclásio acha-se representado por mesopertita/antipertita, em particular junto às bordas mais limpas dos grãos.

\section{Diques microdioríticos}

Estes corpos, intrusivos em rochas charnoquíticas, orientam-se em geral para NW e são cortados por diques de direção NE. As rochas são maciças, de coloração cinzenta escuro a preta, e granulação fina a afanítica. Texturalmente, elas se mostram porfiríticas, com poucos e pequenos fenocristais de plagioclásio e clinopiroxênio, passando porém a arranjos mais intergranulares ou mesmo subofíticos.

Quanto à mineralogia, ao lado de plagioclásio, de forma retangular e alterado freqüentemente em sericita, zeólitas e carbonatos, e clinopiroxênio, de hábito granular a prismático e coloração parda a levemente rosada, elas contêm ainda, na condição de membros da matriz, anfibólio, biotita, opacos, feldspato alcalino, apatita e carbonatos, estes na forma de pequenos glóbulos de dimensões não superiores a $0,5 \mathrm{~mm}$. O anfibólio, substituindo em geral os grãos de clinopiroxênio, é representado por uma variedade de cor verde escuro a verde-acinzentado em Z e também por kaersutita, de bordas esverdeadas. A biotita corresponde a uma variedade vermelha a marromavermelhada em Y-Z e, comumente, forma palhetas pouco definidas, poucas vezes idiomórficas.

A despeito da presença de kaersutita e biotita vermelha, bem como dos glóbulos carbonáticos, essas rochas são petrograficamente referidas como microdioritos, distinguindo-se dos tipos lamprofíricos existentes na área pela presença de fenocristais de plagioclásio e pela ausência de textura panidiomórfica.

\section{Diques lamprofíricos}

A julgar pelas características petrográficas e dados de campo, a maioria das rochas ocorrendo na forma de diques pode ser descrita como lamprofírica.

Texturalmente, são rochas micro- a porfiríticas, com os micro- e fenocristais de clinopiroxênio e olivina $3 / 4 \mathrm{em}$ geral não ultrapassando $20-25 \%$ da moda e, em média, cerca de $10 \% 3 / 4$ imersos em matriz granular muito fina a isotrópica, que, juntamente com os minerais acima e mais a fase vítrea, podem conter plagioclásio com geminação polissintética, biotita, anfibólio, opacos, apatita e produtos de alteração. Em algumas amostras, o plagioclásio, apresentando hábito ripiforme e zoneamento normal, é mineral predominante e tende a exibir arranjo subparalelo. Essas rochas se caracterizam ainda pela presença de macrocristais (xenocristais ou micro xenólitos) de plagioclásio ou de plagioclásio \pm olivina \pm clinopiroxênio e, mais raramente, de anfibólio amarelado com grande número de inclusões. Estruturas ocelares as mais variadas são também reconhecidas.

O clinopiroxênio é idiomórfico, zonado de forma oscilatória, não geminado, e exibe coloração rósea a pardo-amarelada e dimensões centimétricas. Do ponto de vista composicional, corresponde a uma variedade titanífera de diopsídio-augita. Por vezes, ele se faz acompanhar de olivina de composição superior a $\mathrm{Fo}_{65}$, a julgar pelas propriedades ópticas. A sua transformação mais notável é para kaersutita, esta em geral idiomórfica, colorida e presente como prismas curtos ou alongados; em uma única amostra, kaersutita foi também observada na forma de fenocristais centimétricos. A olivina é sempre idiomórfica e pode ser encontrada inalterada ou transformada em agregado consistindo em serpentina \pm clorita \pm talco \pm carbonatos \pm opacos. A biotita é avermelhada a marrom-avermelhada em Y-Z e ocorre como pequenas placas, idiomórficas ou não, que se mostram esqueléticas quando a fase está presente na condição de microfenocristais. Comumente, ela é vista circundando grãos de opacos ou ocupando as bordas de cristais de clinopiroxênio e olivina; por vezes, aparece envolvendo os ocelos, atravessando-os, ou então disposta no interior do material ocelar isotrópico, na forma de minúsculas palhetas. Os opacos, exibindo hábitos e tamanhos os mais variados, estão representados principalmente por magnetita e ilmenita; pirita tem ocorrência restrita aos ocelos. Estes variam na forma e tamanho em função da espessura dos diques e da distância dos contatos, podendo ocorrer como grãos submilimétricos a milimétricos, equidimensionais, isolados ou na forma de agregados. O feldspato alcalino, de forma retangular e geminado segundo Carlsbad, é identificado em ocelos junto ao material isotrópico, mas pode também estar presente em associação com o plagioclásio. O material isotrópico consiste em analcita e/ou vidro e apresenta aspecto variado, incolor e limpo (analcita e vidro) e marrom-avermelhado e sujo (vidro). Ele é encontrado preenchendo os ocelos ou preenchendo os interstícios dos demais minerais. Como acessórios mais comuns, distinguem-se apatita e titanita.

Com base em Le Maitre (1989), as rochas lamprofíricas existentes poderiam corresponder no geral a camptonitos, com algumas amostras caracterizadas como sannaítos, e classificadas petrograficamente como lamprófiros alcalinos. 


\section{CONSIDERAÇÕES FINAIS}

\section{Síntese petrográfica e mineralógica}

As litologias da Ilha dos Búzios podem ser enquadradas em dois grandes conjuntos. O primeiro, envolvendo as rochas félsicas, reúne tipos plutônicos, todos feldspáticos, com e sem quartzo, não portadores de feldspatóides, e consistindo basicamente em álcali feldspato sienitos e quartzo-álcali feldspato sienitos e variedades finas. A eles se juntam as rochas de diques, com mais amplo espectro composicional, passando de tipos quimicamente saturados em $\mathrm{SiO}_{2}$ como traquitos e microssienitos, os mais abundantes, a insaturados, representados por alguns microssienitos, e até mesmo a supersaturados, como riólitos e microgranitos. O segundo inclui as rochas máficas e ultramáficas, invariavelmente presentes na forma de pequenos diques, e que, do ponto de vista petrográfico, são referidas como diabásios, microdioritos e lamprófiros, estas últimas dominantemente do tipo camptonítico, ainda que tenham sido reconhecidas algumas amostras de sannaíto.

Sienitos e traquitos representam mais de $95 \%$ das rochas alcalinas da Ilha, com as primeiras presentes em todos os lugares e apresentando grandes semelhanças petrográficas. A exemplo da Ilha de Vitória, rochas plutônicas básicas não foram encontradas em Búzios, enquanto foiaítos típicos somente estão presentes nas Ilhas do Monte de Trigo e de São Sebastião. Por outro lado, os tipos riolíticos descritos como diques não são petrograficamente riólitos, podendo mesmo corresponder a rochas traquíticas envolvidas em processos de assimilação de quartzo. É oportuno realçar que, do ponto de vista químico, essas rochas não são correlacionáveis aos riólitos estudados por Bellieni et al. (1990), na Ilha de São Sebastião.

Feldspatos constituem o grupo de minerais mais importante das rochas da Ilha. Nos tipos sieníticos e em parte dos diques, eles são universalmente de caráter micromesopertítico, com destaque para o padrão "tigrado" e para a maior dominância do componente albítico. Em menor proporções, exibem intercrescimento criptopertitíco, sendo as fases opticamente homogêneas. As relações texturais indicam que a sua formação se deu posteriormente à das fases fêmicas (clinopiroxênio, anfibólio e biotita). Em outros diques (fonólitos, lamprófiros), feldspato alcalino (sanidina?) e plagioclásio (albita) estão presentes na forma de indivíduos isolados, quer como micro- a fenocristais, quer como membros da matriz, apresentando-se inalterados ou com grau variado de transformação. Quando na condição de fenocristais, com núcleos limpos, os feldspatos são visivelmente de formação anterior aos fêmicos. Quando na matriz de fundo, eles parecem ter-se cristalizado concomitantemente com esses minerais. Feldspatóides têm ocorrência restrita a alguns diques de microssienitos e fonólitos, onde aparecem conjuntamente nefelina e sodalita integrando a matriz granular. Registra-se ainda a presença de analcita, associada ou não a material vítreo, junto à massa fundamental das rochas lamprofíricas.

Os clinopiroxênios correspondem ao principal grupo de ferromagnesianos, variando composicionalmente de tipos diopsídico-augítico a egirínico. Nas variedades lamprofíricas, eles estão representados por augita-diopsídio de natureza titanífera. As transições para termos mais ferrosos (férricos) e sódicos são no sentido do núcleo para as bordas dos grãos, como evidenciado pelo padrão de zoneamento e cores de pleocroísmo. Texturalmente, eles podem se apresentar transformados em anfibólio e/ou biotita, dentro de uma seqüência normal de cristalização magmática, tendo esses dois últimos minerais se originado simultaneamente ao feldspato mesopertítico, já em um estágio mais avançado de cristalização, em que o sistema conta com maior concentração em fluidos aquosos. Nos diques lamprofíricos, aparece também olivina, que, ao lado dos demais ferromagnesianos presentes, hidratados ou não, exibe características de mineralogia primária. Nessas rochas, reconhece-se também a presença de anfibólio do tipo kaersutita, como produto de alteração do clinopiroxênio. Ainda indicativa de formação primária é a presença de anfibólio e/ou biotita em alguns diques básicos mais basálticos, a sugerir que os prováveis representantes parentais das rochas de Búzios tenham sido magmas enriquecidos em fluidos aquosos.

Opacos (dominantemente magnetita e ilmenita), de forma variada, indicativa de fases distintas de crescimento, correspondem ao principal mineral acessório das diversas litologias da Ilha. Com maior ou menor frequiência, estão também presentes apatita, titanita, zircão, fluorita, além de silicatos ricos em Ti e $\mathrm{Zr}$ nas variedades insaturadas. Como produtos de alteração mais comuns, distinguem-se zeólitas, carbonatos, filossilicatos (serpentina, clorita) etc. Por último, mencione-se a existência de glóbulos e estruturas ocelares com mineralogia variada, reunindo principalmente analcita, vidro e/ou carbonatos, sobretudo nas rochas dos diques lamprofíricos. Nestas, as relações texturais com os demais minerais parecem indicar que esses ocelos - de dimensões e formas variadas, além de ocorrendo isoladamente ou como agregados - são fases primárias, o que poderia apontar para a participação de processos de imiscibilidade na geração das rochas alcalinas da Ilha. 


\section{Alojamento dos sienitos}

A presença de xenólitos do tipo I, de dimensões métricas a decimétricas e forma angular a subangular, todos com maior concentração junto á região de contato, além de venulações sieníticas e fragmentação das peças, indicam processo de alojamento da intrusão alcalina pelo mecanismo de "stopping" (Hall, 1987; Marsh, 1982). Em adição a essas características, o exame petrográfico revela que os xenólitos charnoquíticos foram submetidos a fusão parcial e, ainda mais, que os de rochas máficas foram pouco afetados pelo processo, embora os do tipo II coexistentes tenham aparentemente sofrido intensa corrosão magmática. As rochas charnoquíticas têm composição próxima à do eutético granítico, mesmo a baixas pressões de água. Não é fora de propósito afirmar que fragmentos charnoquíticos foram assimilados pelo material sienítico. A coexistência de xenólitos dos tipos I e II nos mesmos locais indica momentos e origem diferentes, com os do tipo II tendo experimentado residência mais prolongada no magma sienítico e, obviamente, sendo de origem anterior. Não existindo tipos intermediários, eles podem representar dois momentos distintos de ascensão da massa magmática. As variações granulométricas nos microssienitos são indicativas de distintas massas magmáticas com diferentes regimes termais, o que significaria que, após o primeiro momento de colocação de parte do magma, que possivelmente não atingiu a sua posição final (Marsh, 1982), novas massas móveis e aquecidas posicionaram-se pelo caminho já aberto, misturando-se às primeiras, ainda não consolidadas. $\mathrm{O}$ alojamento final, cada vez ocupando mais espaço e mais próximo à superfície, deve ter sido progressivo e contínuo, a julgar pelos sienitos e outras feições petrográficas. Com gradientes termais cada vez menores, seria de se esperar granulações mais grossas, mais tardias. A passagem para os sienitos "híbridos", de granulação grossa e com restos de minerais dos charnoquitos, sugere condições diferentes daquelas experimentadas pelos microssienitos. Em qualquer das situações, houve assimilação parcial das encaixantes, alterando a composição da rocha intrusiva, principalmente no que toca à concentração de sílica, e sendo responsável, em parte, pela presença do quartzo. A fusão parcial dos charnoquitos pode ter sido acompanhada pelo aumento da pressão de água, mesmo com queda na pressão total, parte da qual da própria massa em fusão. O aumento da pressão de água pode ter alterado a sequiência de formação dos minerais, levando à cristalização de anfibólio ou biotita no lugar do piroxênio, ao lado do aparecimento de mais quartzo. Essas condições parecem ter sido mais intensas na região de contato com as encaixantes charnoquíticas, como evidenciado pela presença de cavidades miarolíticas e corpos pegmatíticos e pelas mudanças mineralógicas.

Há poucas evidências de cisalhamento ou de deformação plástica, mesmo nos vários contatos. Não ocorrem sienitos cataclásticos ou miloníticos, de monta, indicando ausência de campo de tensões de cisalhamento locais intensos e, se os houve ou há, regionalmente, não há registro de zonas importantes de alívio.

\section{Seqüência cronológica das rochas}

As rochas encaixantes são charnoquitos, notoriamente atribuídos ao Neoproterozóico, e contando com datações radiométricas variadas. As grandes massas reunindo charnoquitos-(meta)máficas em contato e circundadas por sienitos finos, ricos em xenólitos, indicam que as (meta)máficas penetraram os charnoquitos, sendo o conjunto envolvido pelo material sienítico. Este último processo aqueceu suficientemente as rochas e, ao mesmo tempo, mobilizou-as mecanicamente a ponto de levar à formação de "back veining" do charnoquito e dar plasticidade ao conjunto xenolítico.

Sienitos finos, geralmente quartzosos, e sienitos de granulação grossa mostram relações duplas: junto aos contatos, os finos representam faciologia de contato e serviram de "lubrificante" termal para o alojamento dos segundos; em outros locais, formam bolsões e diques aparentemente mais tardios. Longe dos sienitos, os charnoquitos são cortados por rochas máficas não-diabásicas, quase sempre orientadas para NE. Ocasionalmente, ocorrem no quadrante NW, sendo então anteriores, e cortadas por diques NE. Os diques de microssienitos dispõem-se sempre para NE. Alguns diques máficos podem ser sin-plutônicos, uma vez que aparentemente são intrusivos e/ou parcialmente interrompidos nos contatos. Os diques félsicos e máficos alcalinos reúnem rochas com atitudes diversas, ocupando posições NE ou espalhando-se pelos quadrantes NE e NW, e são posteriores aos sienitos.

Nenhuma evidência foi encontrada de que os sienitos estariam cortando outras rochas, a não ser as encaixantes brasilianas. Como tanto os lamprófiros, como os diabásios e traquitos intrudem os sienitos, são eles todos posteriores às rochas plutônicas. Mas, não foram observadas relações elucidativas entre os diques. Uma possível seqüência cronológica para as rochas de Búzios é sugerida com base nas informações de campo:

- Embasamento Precambriano charnoquítico, milonítico; 
- diques máficos, básicos [(meta) máficas xenolíticas];

- rochas sieníticas finas, parte dos diques do embasamento;

- sienitos;

- $\quad$ sincrônica e posteriormente aos sienitos, diques máficos alcalinos e microssienitos;

- diques alcalinos em geral, em particular os tipos félsicos;

- $\quad$ atividade tardia a pós-magmática e hidrotermal.

\section{Evolução das rochas alcalinas}

Em que pese à limitação dos dados disponíveis, eles permitem observar que as rochas da Ilha dos Búzios, em particular as variedades intrusivas, exibem grande homogeneidade química e mineralógica. Além disso, se excluídos os tipos mais básicos de afinidade dominantemente gábrica, presentes nas ocorrências de São Sebastião e Monte de Trigo, nota-se que elas apresentam muitas similaridades com as litologias características das ilhas vizinhas, aí incluída a de Vitória. No geral, são rochas evoluídas, de natureza sienítica, com as principais diferenças correndo aparentemente por conta do nível de erosão desses corpos e das dificuldades de amostragem. Rochas supostamente mais primitivas são encontradas nessas quatro ilhas apenas na forma de pequenos diques, comumente de dimensões decimétricas. Essas similaridades levam a considerar que elas estão associadas à mesma atividade magmática e que, com base em evidências mineralógicas, texturais e químicas, evoluíram por processos de cristalização fracionada a partir de magma parental de natureza basanítica ou nefelinítica, como tem sido postulado para outras ocorrências alcalinas brasileiras (p.e. Piratini, Barbieri et al., 1987; Juquiá, Beccaluva et al., 1992; Lages, Traversa et al., 1996). A participação de processos de assimilação crustal tem sido também admitida, ainda que subordinadamente (Tunas; Gomeset al., 1987; Juquiá, Beccaluva et al., 1992).

\section{Formas e dimensões dos corpos alcalinos}

Os corpos alcalinos da Ilha de São Sebastião, sendo os de Serraria e São Sebastião os mais bem preservados, possuem forma elíptica, com eixos, respectivamente, de 1112 km e 8-9 km, numa relação de 1,2-1,4:1, e estão orientados para N50E. Os corpos menos erodidos têm áreas em torno dos $65 \mathrm{~km}^{2}$. A Ilha do Monte de Trigo, consideravelmente menor que a anterior, apresenta forma elíptica, com o eixo maior alcançando $1,5 \mathrm{~km}$ e o menor $1,1 \mathrm{~km}$, numa relação de 1,36: 1 . Ela representa a porção emersa central de intrusão maior, a julgar pelas dimensões dos corpos vizinhos e pela ausência de evidências de proximidade de contato com as encaixantes (Coutinho \& Melcher, 1973). A Ilha de Vitória tem centro submerso, a oeste, indicado pela intersecção dos diques radiais, curvos nas porções distais, e pelas curvas isonormativas concêntricas de $\mathrm{Q}$ e $\mathrm{Ne}$ (Motoki, 1986). A mais supersaturada $(\mathrm{Q}=2)$ situa-se a $3,8 \mathrm{~km}$ do centro, enquanto que a de $\mathrm{Q}$ e $\mathrm{Ne}=0$ está localizada a $2 \mathrm{~km}$ na direção N50E, com proporção entre os eixos de 1,2 e 1,4 . $\mathrm{O}$ raio da curva $\mathrm{Q}=\mathrm{Ne}=0$ no semi-eixo menor seria de $1,8 \mathrm{~km}$. A forma elíptica da intrusão pode ser verificada pela sua convexidade para leste e explicaria o curvamento dos diques radiais, assim como as duas envoltórias isonormativas a partir de $\mathrm{Ne}=6$. O corpo poderia ter, pelo menos, eixos com $6 \mathrm{~km} \mathrm{e} 8 \mathrm{~km}$.

As curvas batimétricas das proximidades das Ilhas de Búzios e Vitória indicam irregularidades e quebras no padrão batimétrico, compatíveis com possíveis extensões submersas desses corpos (Figura 3). É possível que Búzios represente a porção marginal de corpo alcalino maior, de forma elíptica, com eixo maior N50E, alinhado às outras ocorrências.

O Saco Grande representaria a configuração atual, semi-elíptica da borda norte do corpo que se prolongaria para S. São factíveis valores de 7-9 e 9-11 km para os possíveis eixos do corpo de Búzios. Assim, as rochas sieníticas estender-se-iam para NE, E, SE, S e SW. O núcleo da intrusão estaria pelo menos $2 \mathrm{~km}$ a $\mathrm{S}$ do centro atual do Saco Grande (Figuras 1, 2 e 3). Feições sugestivas da proximidade desse núcleo consistem na presença de veios e diques de rochas insaturadas na porção oriental da Ilha, como remanescentes de um corpo erodido de maiores dimensões. Nesse cenário, a Ilha Somítica (Figura 2) corresponderia a uma extensão de Búzios para $S$. Igualmente indicativas desse foco submerso situado a sul da chamada Ponta Sul seriam o contorno da linha de praia (Saco Grande), a disposição dos topos das colinas e a orientação dos diques radiais e dos alinhamentos fotogeológicos. É interessante notar o alinhamento dos corpos alcalinos das Ilhas de Vitória, Búzios e São Sebastião (Mirante) e das ilhas situadas mais a sul (Alcatrazes, Laje de Santos e Queimada Grande).

O exame bibliográfico e os dados constantes deste trabalho permitem verificar a similaridade dos corpos sieníticos das Ilhas de Vitória, Búzios e São Sebastião e sugerir o seu relacionamento com as grandes estruturas vizinhas comuns, especialmente a Falha de Santos. 


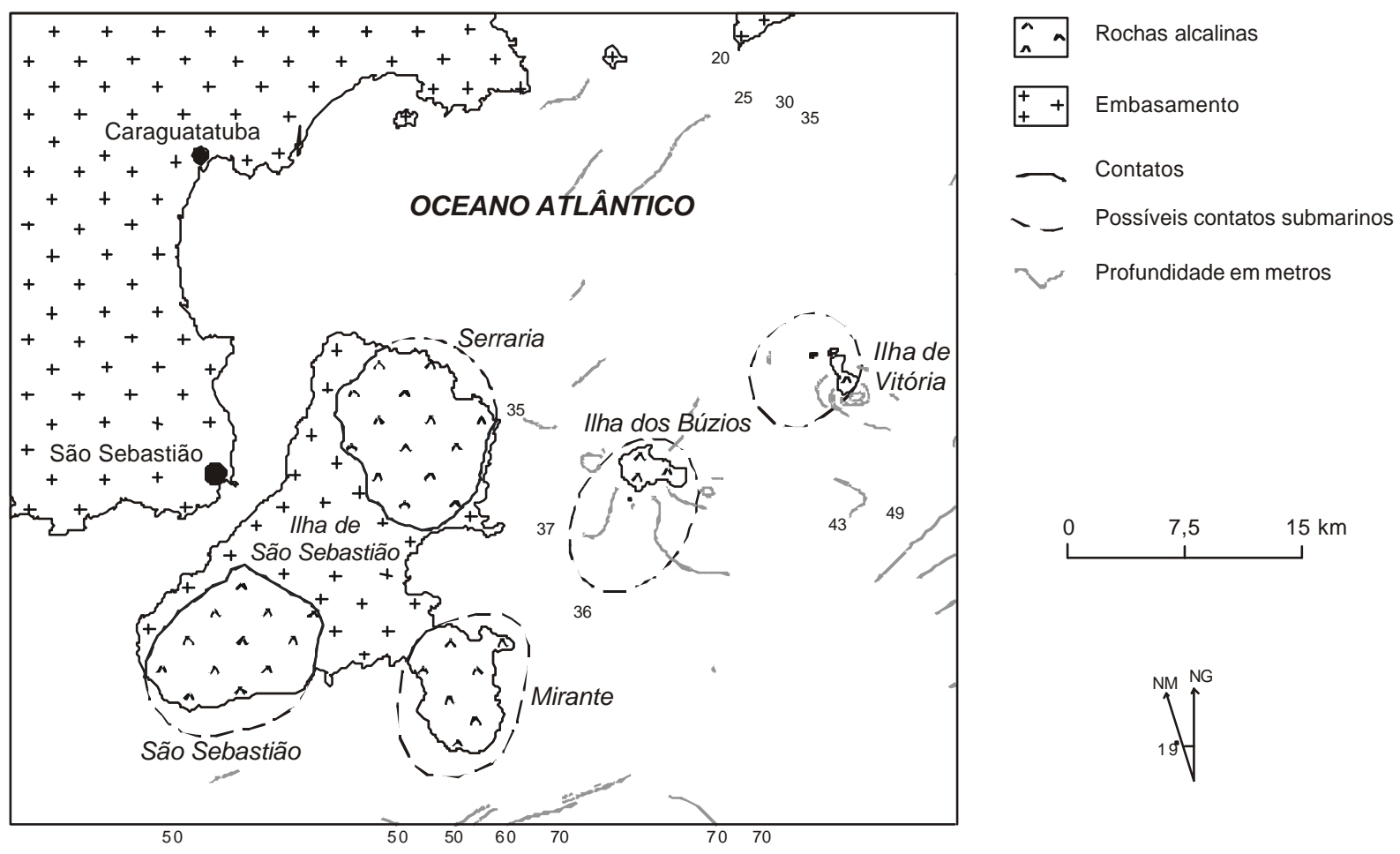

Figura 3: Distribuição e dimensões dos corpos alcalinos das llhas de Vitória, Búzios e São Sebastião (extraído de Alves, 1997).

\section{AGRADECIMENTOS}

Estes são devidos à FAPESP pelo apoio financeiro (Processo n. 97/01210-4, C.B.G.).

\section{REFERÊNCIAS BIBLIOGRÁFICAS}

ALMEIDA, F.F.M. (1983) Relações tectônicas das rochas alcalinas mesozóicas da região meridional da plataforma Sul-americana. Revista Brasileira de Geociências, v. 13, p. 139-158.

ALVES, F. R. (1997) Contribuição ao conhecimento geológico e petrográfico das rochas alcalinas da Ilha dos Búzios, SP. São Paulo, 274p. Tese (Doutorado) - Instituto de Geociências, Universidade de São Paulo.

ALVES, F.R; GOMES, C.B. (1999) As rochas alcalinas do litoral norte do Estado de São Paulo: caracterização petrográfica e modelagem geológica das ocorrências da Ilha dos Búzios. In: SIMPÓSIO DE GEOLOGIA DO SUDESTE, 6., São Pedro, 1999. Boletim de Resumos. São Pedro, SBG/UNESP. p. 62.
ALVES, F.R.; GOMES, C.B. (2000) Geological and petrographic study from the Búzios Island, northern coast of the São Paulo State, SE Brazil. In: INTERNATIONAL GEOLOGICAL CONGRESS, 31., Rio de Janeiro, Brazil, 2000. Rio de Janeiro. (CD-ROM).

ALVES, F.R.; GOMES, C.B.; ENRICH, G.E. (1999) Estudo geoquímico e isotópico dos minerais e das rochas alcalinas da Ilha dos Búzios, litoral norte, SP. In: SIMPÓSIO DE GEOLOGIA DO SUDESTE, 6., São Pedro, 1999. Boletim de Resumos. São Pedro, SBG/UNESP. p. 60.

ALVES, F.R.; GOMES, C.B.; ENRICH, G.E. (2000) Mineral chemistry of alkaline rocks of Búzios Island, northern coast of São Paulo State, SE Brazil. In: INTERNATIONAL GEOLOGICAL CONGRESS, 31., Rio de Janeiro, Brazil, 2000. Rio de Janeiro. (CD-ROM).

BARBIERI, M.; BECCALUVA, L.; BROTZU, P.; CONTE, A.; GARBARINO, C.; GOMES, C.B.; LOSS, E.L.; MACCIOTTA, G.; MORBIDELLI, L.; SCHEIBE, L.F.; TAMURA, R.M.; TRAVERSA, G. (1987) Petrological and geochemical studies of alkaline rocks from continental Brazil. 1. The phonolite suite from Piratini, RS. Geochimica Brasiliensis, v. 1, p. 109-138. 
BECCALUVA, L.; BORN, H.; BROTZU, P.; COLTORTI, M.; CONTE, A.M.; GARBARINO, C.; GOMES, C.B.; LOSS, E.L.; MACCIOTTA, G.; MORBIDELLI, L.; RUBERTI, E.; SIENA, F.; TRAVERSA, G. (1992) Fractional crystallization and liquid immiscibility processes in the alkalinecarbonatite complex of Juquiá (São Paulo State, Brazil). Journal of Petrology, v. 33, p. 1371-1404.

BELLIENI, G.; MONTES-LAUAR, C.R.; DE MIN, A.; PICCIRILLO, E.M.; CAVAZZINI, G.; MELFI, A.J.; PACCA, I.G. (1990) Early and Late Cretaceous magmatism from São Sebastião Island (SE-Brazil): geochemistry and petrology. Geochimica Brasiliensis, v. 4, p. 59-83.

BJÖRNBERG, A.J.S; ELLERT, R. (1955) Observações geológicas e petrográficas sobre a Ilha dos Búzios. Anais da Academia Brasileira de Ciências, v. 27, p.169-182.

COUTINHO, J.M.V.; MELCHER, G.C. (1973) Levantamento geológico e petrográfico na Ilha do Monte de Trigo (Litoral Norte de São Paulo, Brasil). Revista Brasileira de Geociências, v. 3, p. 243-256.

ENRICH, G. E.; RUBERTI, E. (1999) Geologia da Ilha do Monte de Trigo, litoral norte do Estado de São Paulo. In: SIMPÓSIO DE GEOLOGIA DO SUDESTE, 6., São Pedro, 1999. Boletim de Resumos. São Pedro, SBG/UNESP. p. 67.

FREITAS, R.O. (1947) Geologia e petrologia da Ilha de São Sebastião. Boletim da Faculdade de Filosofia, Ciências e Letras. Universidade de São Paulo, v. 85, p. 1-244.

FREITAS, R.O. (1976) Definição petrológica, estrutural e geotectônica das cintas orogênicas antigas do litoral norte do Estado de São Paulo. Boletim do Instituto Geológico, v. 1, p. 1-176.

GARDA, G.M. (1995) Os diques básicos e ultrabásicos da região costeira entre as cidades de São Sebastião e Ubatuba, Estado de São Paulo. São Paulo, 156p. Tese (Doutorado) - Instituto de Geociências, Universidade de São Paulo.

GOMES, C.B.; BARBIERI, M.; BECCALUVA, L.; BROTZU, P.; CONTE, A.M.; GARBARINO, C.; MACCIOTTA, G.; MELLUSO, L.; MORBIDELLI, L.; RUBERTI, E.; TAMURA, R.M.; TRAVERSA, G. (1987) Petrological and geochemical studies of alkaline rocks from continental Brazil. 2. The Tunas mas- sif, State of Paraná. Geochimica Brasiliensis, v. 1, p. 201-234.

HALL, A. (1987) Igneous petrology. London, Longman Science and Techonology. 573p.

HENNIES, W.T. (1964) Rochas alcalinas de São Sebastião. In: CONGRESSO BRASILEIRO DE GEOLOGIA, 18, Poços de Caldas, MG.

HENNIES, W.T.; HASUI, Y. (1968) Geocronologia das rochas eruptivas da Ilha de São Sebastião, SP. In: CONGRESSO BRASILEIRO DE GEOLOGIA, 22, Belo Horizonte, MG. Resumo das Comunicações. Belo Horizonte, SBG. p. 145-148.

HENNIES, W.T. ; HASUI, Y. (1977) Contribuição ao reconhecimento da geologia da Ilha de São Sebastião. In: SIMPÓSIO DE GEOLOGIA REGIONAL, São Paulo, 1977. Atas. São Paulo, SBG. p.199-209.

LE MAITRE, R.W. (ed.) (1989) A classification of igneous rocks and glossary of terms. Oxford, Blackwell. $193 p$.

MARSH, D.B. (1982). On the mechanics of igneous diapirism, stopping, and zone melting. American Journal of Science, v. 82, p. 808-855.

MOTOKI, A. (1986) Geologia e petrologia do maciço alcalino da Ilha de Vitória, SP. São Paulo, 245p. Tese (Doutorado) - Instituto de Geociências, Universidade de São Paulo.

MOTOKI, A.; GOMES, C.B. (1984) Caracterização geológica e petrográfica do maciço alcalino da Ilha de Vitória, SP. In: CONGRESSO BRASILEIRO DE GEOLOGIA, 33., Rio de Janeiro, 1984. Anais. Rio de Janeiro, SBG. v. 9, p. 4392-4399.

MOTOKI, A.; GOMES, C.B.; DUTRA, C.V. (1987) Assimilação de rochas encaixantes pelo magma nefelina sienítico do maciço alcalino da Ilha de Vitória, SP. In: CONGRESSO BRASILEIRO DE GEOQUÍMICA, 1., Porto Alegre, 1987. Anais. Porto Alegre, SBGq. v. 1, p. 375-397.

SMITH, J.V. ; BROWN, W.L. (1988) Feldspar minerals: v.1. Berlin, Springer-Verlag, 828p.

TRAVERSA, G.; BARBIERI, M.; BECCALUVA, L.; COLTORTI, M.; CONTE, A.M.; GARBARINO, C.; GOMES, C.B.; MACCIOTTA, G.; MORBIDELLI, L.; RONCA, S.; SCHEIBE, L.F. (1996) Mantle sources and differentiation of alkaline magmatic suite of Lages, Santa Catarina, Brazil. European Journal of Mineralogy, v. 8, p. 193-208. 